\title{
ANÁLISIS \\ Reflexiones sobre el proceso de integración de la Alianza del Pacífico desde la perspectiva de la competitividad e inversión en ciencia y tecnología: retos para la integración comercial futura
}

\section{Reflections on the process of the Pacific Alliance integration from the perspective of Competitiveness and Investment in Science and Technology: Challenges for future Commercial Integration}

\author{
Ángel Licona Michel ${ }^{1}$ \\ DOI: $10.32870 /$ mycp.v9i25.597 \\ Angel Licona Michel
José Ernesto Rangel Delgado \\ Angel Licona Michel
José Ernesto Rangel Delgado ${ }^{2}$
Juan González García ${ }^{3}$
}

\begin{abstract}
Resumen
Actualmente, los procesos de integración económica y comercial caracterizan las relaciones entre las regiones y países del mundo, sin excepción. Con ese objetivo, en 2011 en América Latina, se formalizó la creación de la llamada Alianza del Pacífico (AP), conformada por México, Chile, Colombia y Perú. Con dicha alianza, estos cuatro países, pretendieron incrementar sus flujos de comercio e inversión mutuos, para incentivar su producción de bienes y servicios. El objetivo del presente artículo es analizar desde la creación de la AP, los factores que explican la evolución del comercio e inversión entre
\end{abstract}

los cuatro países, empleando el método exploratorio. Los resultados, indican que hasta el momento, la AP dista mucho de alcanzar su objetivo de mayor integración y crecimiento económico en cada país. La principal contribución del artículo es contrastar los objetivos que la teoría de la integración económica postula versus los resultados alcanzados en la práctica por la AP.

Palabras clave: Competitividad, Inversión en I\&D, Comercio, Crecimiento Económico, Integración Económica.

Artículo recibido el 14 de agosto de 2018 y dictaminado el 07 de junio de 2019.

1. Centro de Estudios e Investigaciones sobre la Cuenca del Pacífico de la Universidad de Colima, ubicado en Avenida Gonzalo de Sandoval 444, Colonia las Víboras, C.P. 28040, Colima, Colima, México. ORCID: https://orcid.org/0000-0001-6245-8269. Correo electrónico: almichel@ucol.mx

2. Centro de Estudios e Investigaciones sobre la Cuenca del Pacífico de la Universidad de Colima, ubicado en Avenida Gonzalo de Sandoval 444, Colonia las Víboras, C.P. 28040, Colima, Colima, México. ORCID: https://orcid.org/0000-0003-1392-9153. Correo electrónico: erangel@ucol.mx

3. Centro de Estudios e Investigaciones sobre la Cuenca del Pacífico de la Universidad de Colima, ubicado en Avenida Gonzalo de Sandoval 444, Colonia las Víboras, C.P. 28040, Colima, Colima, México. ORCID: https://orcid.org/0000-0003-1458-8047. Correo electrónico: jgogar@ucol.mx 


\section{Abstract}

Currently, economic and commercial integration processes characterize the relationships between regions and countries of the world, without exception. With that in mind, in 2011 in Latin America, the creation of the so-called Pacific Alliance (PA) was formalized, conformed by Mexico, Chile, Colombia, and Peru. With this alliance, these four countries sought to increase their mutual trade and investment flows, to encourage their production of goods and services. The objective of this article is to analyze from the creation of the PA, the factors that explain the evolution of trade and investment between the four countries, using the exploratory method. The results indicate that to this moment, the PA is far from achieving its objective of greater integration and economic growth in each country, this being its main contribution: contrast the objectives that the theory of economic integration postulates versus the results achieved in practice by the PA.

Keywords: Competitiveness, Investment \& Development, Trade, Economic Growth, Economic Integration

\section{Introducción}

Chile, Colombia, México y Perú en 2011 crearon la llamada AP, para formar un mayor mercado mutuo y hacer posible el incremento de la economía. Los cuatro países tienen una población superior a los 200 millones de habitantes, según datos del Banco Mundial (BM, 2019d), la población registró un ingreso per cápita que no supera los $\$ 14,000$ dólares, lo cual refleja que deben estimular sus tasas de crecimiento económico para mejorar la riqueza de la AP.

Por ejemplo, entre 2011 y 2017 cada país, registró un modesto crecimiento del producto interno bruto (PIB). Efectivamente, Chile, 3.2 por ciento; Colombia de 3.9; México de 2.8 y Perú de 4.3 por ciento. El crecimiento del PIB es más alto en Chile si se considera el promedio de 1990 a 2017 donde alcanza 4.7 por ciento, Colombia 3.6, México 2.7 y Perú 4.3 (BM, 2019d).

El país que tiene tasas de crecimiento más bajas en el PIB es México, pero de igual manera es la economía más grande conforme al valor de su PIB, lo cual le permite ser un mercado que dinamiza el comercio y las inversiones de sus socios comerciales de la AP. Las naciones de la AP buscan que sus economías sean competitivas para fortalecer sus industrias y el ingreso de su población, de acuerdo con el reporte global de competitividad 2018, Chile ocupa la posición 33 en el ranking global, le sigue México en la 51, Colombia en el lugar 66 y Perú en el 72 (The World Economic Forum [WEF], 2019). Asimismo, invierten en promedio menos del 0.5 por ciento del PIB en Investigación y Desarrollo (I\&D) que les permita crear ciencia y tecnología, situación que limita las posibilidades de alcanzar mayores niveles de competitividad y consolidar su 
integración comercial con una significativa participación de exportaciones e importaciones entre los miembros de la AP (BM, 2019b).

En 1993 el comercio total entre Chile y México sumó 329 millones 851 mil dólares, con Colombia 322 millones 977 mil dólares y con Perú 263 millones 975 mil dólares, para 2011 fecha de conformación de la AP, el comercio de Chile, superó los 4 mil millones de dólares, Colombia, 6 mil millones y Perú, mil 800 millones de dólares (Secretaría de Economía [SE], 2019a). Dichas cifras, comparadas con el comercio de México, que supera los 400 mil millones de dólares, no se acercan ni al uno por ciento, lo mismo sucede con la Inversión Extranjera Directa (IED) que no representa el uno por ciento de lo que recibe México (SE, 2019b).

El objetivo de esta investigación es, analizar la relación que existe entre la competitividad, el comercio exterior y la inversión en I\&D entre los países de la AP. Hasta ahora, la inversión en I\&D, no ha sido un factor que propicie la mayor integración comercial que impulse el crecimiento de las economías y de su ingreso per cápita. La hipótesis que se plantea es que el bajo nivel de inversión en I\&D en los países de la AP afecta los niveles globales de competitividad, la economía e impide la consolidación de la integración comercial subregional.

El artículo se encuentra estructurado de la siguiente manera: una introducción, un apartado de consideraciones teóricas; otro de la participación de las exportaciones e importaciones en el PIB de los países de la AP; uno más de crecimiento económico y evolución del ingreso per cápita de la AP; otro más que analiza la inversión I\&D de la AP. Un penúltimo que analiza la posición alcanzada en los pilares de la competitividad en la AP, comercio e IED en México de la AP y un apartado de reflexiones finales.

\section{Consideraciones teóricas}

Los países de la AP, estimulan el crecimiento de la economía por medio de políticas comerciales eliminando aranceles en los productos que se exportan e importan, dinamizando las transacciones comerciales e inversiones. Con la reducción o eliminación de aranceles las empresas de cada país tienen más competencia que exige mejorar procesos y productos, ante ello se ven en la necesidad de mayor innovación que impulse la producción, así como la competitividad de bienes y servicios creados para un mercado, que hace crecer tanto la oferta como la demanda. 
North (1993), indica que las instituciones determinan las oportunidades que existen en la sociedad y reducen la incertidumbre al proporcionar una estructura a la vida diaria por medio de leyes, normas y políticas, acordes a las nuevas condiciones en las cuales se desempeña una nación, por los avances de la ciencia y la tecnología, que exige una nueva clase empresarial, al igual una nueva clase política que apuesta por el futuro en procesos y productos.

En este sentido, los países de la AP, se someten a un proceso en el cual sus instituciones de tipo económico, crean leyes, normas y políticas que facilitan el comercio y las inversiones. En efecto, en 2011 crearon un Protocolo Comercial (Alianza del Pacífico, 2019a), buscando dar certeza al desplazar productos entre sus mercados, disminuyendo restricciones, de igual manera permiten que el capital de las empresas y empresarios, puedan moverse con el respaldo del gobierno de cada nación, teniendo la convicción que sus inversiones y derechos de propiedad serán respetados para que el progreso y la innovación de procesos, así como de productos, mantengan un ritmo de crecimiento.

El protocolo comercial creado por los países miembros de la AP, establece las reglas del proceso de integración:

Artículo 1.1: Establecimiento de una Zona de Libre Comercio (ZLC)

Las partes, de conformidad con lo dispuesto en el Artículo XXIV del Acuerdo General sobre Aranceles Aduaneros y Comercio de 1994 y el artículo V del Acuerdo General sobre el Comercio de Servicios, que forman parte del Acuerdo de Marrakech por el que se establece la Organización Mundial del Comercio, establecen una zona de libre comercio. (Alianza del Pacífico, 2019b, p.1-1)

Para entender el establecimiento de una ZLC, tomamos en cuenta la propuesta de Balassa (1980), en la cual se establece a la ZLC como una de las cinco etapas propias de la integración económica en tanto proceso sujeto a economías de escala y por supuesto a la desaparición de barreras arancelarias que se sustentan en instituciones que dinamizan el comercio entre países.

Naciones en favor de estimular el comercio, crearon instituciones internacionales como el Acuerdo General de Aranceles y Comercio (GATT), transformado más tarde en la Organización Mundial del Comercio (OMC). De tal forma que desde su nacimiento impulsan mejores prácticas para liberalizar el comercio (Krugman, Obstfeld, \& Melitz, 2012; Appleyard \& Field, 2003; Schettino, 1995). Tener mayor presencia en los mercados internacionales exige facilitar el comercio disminuyendo o eliminando los impuestos a los 
productos provenientes del exterior, así como haciendo eficiente los trámites administrativos.

Los países de la AP, se convierten en miembros del GATT, Chile 16 de marzo de 1949, Perú el 7 de octubre de 1951, Colombia el 3 de octubre de 1981 y México el 24 de agosto de 1986, los cuatro con la sustitución del GATT por la OMC, son sus miembros desde que entra en funciones el 1 de enero de 1995 (Organización Mundial del Comercio [OMC], 2019). Con ello la AP muestra que tiene compromisos de estimular la apertura del mercado, por medio de políticas comerciales, en pro de incrementar el comercio con el exterior y establecer alianzas con los mercados en los cuales existe un intercambio de bienes y servicios. De igual manera, como ya mencionamos los países de la AP firmaron un protocolo comercial que tiene como base los Acuerdos de Marrakech de 1994, año en que se crea la OMC.

Sumado a esa institucionalización que impulsa el libre comercio en el marco de la OMC, los países integrados de la AP, buscan tener mayor presencia en los mercados internacionales, jugando estrategias para impulsar el comercio por medio de la apertura al exterior como un solo mercado, como es el caso de una ZLC. Al interior de la ZLC, los consumidores ganan al contar con una mayor oferta de mercancías y de servicios que satisfacen sus diversas necesidades, por su lado los productores al tener mayor competencia se ven obligados en mejorar sus procesos de producción para satisfacer sus necesidades en tanto ZLC, pero también detectando nuevos mercados hacia fuera de la zona para posicionar sus mercancías excedentes.

Al tener firmado un protocolo comercial entre otros documentos, los países de la AP, tienen claridad en la relevancia de los derechos de propiedad, los cuales son exigidos y respetados en el seno de las economías que se integran para favorecer la apertura de libre mercado, creando reglas que den certidumbre y fortalezcan la confianza de inversionistas nacionales y extranjeros, lográndose con leyes, normas y políticas impulsadas y respaldadas por medio de sus instituciones económicas.

Los derechos de propiedad estimulan los flujos de capital hacia las actividades productivas y fomentan el crecimiento de la economía, el comercio y la innovación tecnológica en procesos y productos. La protección de derechos de propiedad también incrementa el mejoramiento de la infraestructura que permite elevar la oferta y demanda, así como transferencias de tecnología que impulsan la competitividad de personas y empresas (Yusuf \& Stiglitz, 2002). 
Los países de la AP, para alcanzar la consolidación de sus economías necesitan exportar e importar más bienes, buscando que la oferta y la demanda en sus mercados contribuyan en dinamizar la producción y el consumo. En este contexto para que los mercados puedan estar interactuando, necesitan la adquisición de maquinaria y técnicas que ayuden a las empresas e industrias en mejorar sus procesos de producción, ello permitirá el incremento de la producción e impulsará las exportaciones e importaciones entre sí. En el caso del comercio realizado entre México, Chile, Colombia y Perú, se detecta un crecimiento en el intercambio de bienes que se compran y venden (ver tabla 7). Ganando los consumidores y productores por contar con un mercado más grande que estimula la oferta y la demanda.

Porter (1999), indica que tanto la rivalidad entre competidores que participan en el mercado, el poder de negociación de compradores y proveedores, como la entrada de productos sustitutos por la llegada de nuevas empresas, son aspectos que exigen la unidad entre el grupo de empresas e industrias que las haga fuertes ante las instituciones, para adecuar las leyes, normas y políticas a las mejoras en procesos y productos, así como generar condiciones para incrementar tanto la demanda como la oferta dinamizando el crecimiento de los mercados. En este contexto los países de la AP se integran quitando obstáculos al comercio y a las inversiones, teniendo más competidores y un mercado potencial de consumidores para compras y ventas que supera los 200 millones de la población en conjunto de los cuatro países de la AP (Alianza del Pacífico, 2019a).

Es así, que la apertura de mercado en la cual operan los países de la AP, también los obliga al logro de mayor competitividad, y ello involucra a todos los actores de la sociedad, políticos, económicos, sociales y tecnológicos. De tal forma que, la competitividad de cada país es determinada, por otra suerte de institucionalidad como lo son los doce pilares según el Foro Económico de Davós (WEF, por sus siglas en inglés), que reflejan los avances o retrocesos alcanzados por los países.

Los doce pilares de la competitividad de acuerdo con el WEF, son las instituciones, infraestructura, ambiente macroeconómico, salud y educación básica, educación superior y capacitación, eficiencia en mercado de bienes, eficiencia en mercado laboral, desarrollo de mercado financiero, preparación tecnológica, tamaño de mercado, sofisticación empresarial, innovación, los cuales permiten detectar los logros de México, Chile, Colombia y Perú (WEF, 2019). 
Los países conforme avanzan en su competitividad, también liberan sus mercados de obstáculos al comercio, impulsando las exportaciones y ello, de igual manera, los obliga a recibir más importaciones para dinamizar sus mercados, generando una interdependencia de compras y ventas entre sí, fortaleciendo su integración para cubrir diversas necesidades en todos los sectores que participan en sus propios mercados.

\section{Participación de las exportaciones e importaciones en el PIB de los países de la AP}

Como hemos mencionado los países de la AP son miembros de la OMC. De igual manera, dichos países eliminan barreras al comercio exterior entre ellos mismos. Lo cual permitirá, con el paso de los años, tener una mayor participación de las exportaciones e importaciones. Asimismo, la AP muestra al mundo que tienen compromisos de estimular la apertura del mercado, con políticas comerciales que disminuyen aranceles, entre otros aspectos, en pro de incrementar el comercio entre sí y con el exterior para establecer alianzas con mercados más allá de su economía fortalecida en tanto ZLC.

De acuerdo con datos del BM (2019c), entre 1990 y 2017, las exportaciones, es decir los bienes que venden las empresas a otras naciones en los países de la AP representaron para el PIB, en el caso de Chile, un promedio de 32.93 por ciento, para Colombia 16.50 por ciento, México 26.04 por ciento y Perú 20.49 por ciento. (Tabla 1 ).

En lo que corresponde a las importaciones, es decir las compras de bienes que hacen los países de la AP representaron en el PIB durante 1990 a 2017 un promedio de 29.8 por ciento en Chile, de 19.6 por ciento para Colombia, 27.6 por ciento en México y de 20.4 por ciento en Perú (tabla 2), lo cual indica que en Colombia y México las importaciones tienen mayor participación en el PIB y en Chile como en Perú son las exportaciones las que tienen una mayor presencia en el PIB, pero en las cuatro economías se muestra un crecimiento en la participación del mercado exterior en su PIB, ello por sus políticas comerciales de apertura que los conectan más con el mercado mundial. 


\section{Tabla 1}

Porcentaje de participación de las exportaciones en el PIB de los países de la AP

\begin{tabular}{|c|c|c|c|c|}
\hline 1990 & 32.5 & 18.9 & 18.7 & 15.7 \\
\hline 1991 & 31.3 & 19.1 & 16.4 & 12.1 \\
\hline 1992 & 29.0 & 16.5 & 15.3 & 12.5 \\
\hline 1993 & 25.9 & 15.2 & 12.3 & 12.3 \\
\hline 1994 & 27.5 & 15.0 & 13.4 & 12.8 \\
\hline 1995 & 28.6 & 14.5 & 24.1 & 12.6 \\
\hline 1996 & 26.6 & 15.2 & 26.0 & 13.3 \\
\hline 1997 & 26.5 & 14.8 & 24.3 & 14.5 \\
\hline 1998 & 25.5 & 15.0 & 24.6 & 13.7 \\
\hline 1999 & 28.8 & 18.3 & 24.6 & 15.4 \\
\hline 2000 & 30.5 & 15.9 & 25.4 & 16.8 \\
\hline 2001 & 32.4 & 15.4 & 22.7 & 16.6 \\
\hline 2002 & 32.8 & 14.8 & 22.6 & 17.3 \\
\hline 2003 & 35.7 & 16.6 & 24.4 & 19.0 \\
\hline 2004 & 39.8 & 16.8 & 28.4 & 22.9 \\
\hline 2005 & 40.2 & 17.0 & 30.4 & 26.8 \\
\hline 2006 & 43.8 & 17.8 & 27.3 & 30.5 \\
\hline 2007 & 45.1 & 16.5 & 27.5 & 31.5 \\
\hline 2008 & 41.4 & 18.1 & 27.7 & 29.7 \\
\hline 2009 & 37.0 & 16.4 & 27.2 & 26.4 \\
\hline 2010 & 37.7 & 16.4 & 29.7 & 27.8 \\
\hline 2011 & 37.8 & 19.3 & 31.0 & 30.5 \\
\hline 2012 & 34.1 & 18.8 & 32.3 & 27.4 \\
\hline 2013 & 32.2 & 18.1 & 31.3 & 24.8 \\
\hline 2014 & 33.1 & 16.6 & 31.9 & 22.6 \\
\hline 2015 & 29.4 & 15.7 & 34.6 & 21.3 \\
\hline 2016 & 28.2 & 14.5 & 37.1 & 22.4 \\
\hline 2017 & 28.7 & 14.6 & 37.9 & 24.3 \\
\hline Promedio & 32.93 & 16.50 & 26.04 & 20.49 \\
\hline
\end{tabular}

Fuente: Elaboración propia con base en datos del Banco Mundial al mes de mayo (2019e), disponible en: https://datos.bancomundial.org/indicador/NE.EXP.GNFS.ZS?view=chart 
Reflexiones sobre el proceso de integración de la Alianza del Pacífico desde la perspectiva de la competitividad e inversión en ciencia y tecnología: retos para la integración comercial futura

Tabla 2

Porcentaje de participación de las importaciones en el PIB en los países de la AP

\begin{tabular}{|c|c|c|c|c|}
\hline 1990 & 29.3 & 15.9 & 19.8 & 13.8 \\
\hline 1991 & 26.8 & 14.4 & 19.4 & 14.3 \\
\hline 1992 & 27.3 & 17.1 & 20.3 & 15.4 \\
\hline 1993 & 27.7 & 21.0 & 15.5 & 16.2 \\
\hline 1994 & 25.8 & 20.9 & 17.3 & 16.2 \\
\hline 1995 & 26.3 & 21.0 & 22.2 & 18.3 \\
\hline 1996 & 28.1 & 20.8 & 24.4 & 18.3 \\
\hline 1997 & 28.5 & 20.8 & 24.4 & 19.0 \\
\hline 1998 & 28.8 & 20.9 & 26.4 & 19.3 \\
\hline 1999 & 26.6 & 17.8 & 26.0 & 17.8 \\
\hline 2000 & 28.8 & 16.8 & 27.0 & 18.8 \\
\hline 2001 & 30.7 & 18.5 & 24.5 & 18.5 \\
\hline 2002 & 30.6 & 18.2 & 24.1 & 18.0 \\
\hline 2003 & 30.7 & 19.9 & 25.8 & 18.6 \\
\hline 2004 & 29.9 & 19.1 & 30.0 & 19.0 \\
\hline 2005 & 31.5 & 20.5 & 32.0 & 20.5 \\
\hline 2006 & 29.3 & 22.0 & 28.8 & 21.2 \\
\hline 2007 & 31.3 & 20.7 & 29.3 & 24.2 \\
\hline 2008 & 39.4 & 21.1 & 30.1 & 28.7 \\
\hline 2009 & 29.3 & 18.7 & 28.8 & 21.7 \\
\hline 2010 & 31.3 & 18.0 & 31.1 & 23.8 \\
\hline 2011 & 34.4 & 20.2 & 32.4 & 25.5 \\
\hline 2012 & 34.1 & 20.0 & 33.5 & 25.2 \\
\hline 2013 & 32.8 & 19.9 & 32.5 & 25.0 \\
\hline 2014 & 32.2 & 20.9 & 33.1 & 24.2 \\
\hline 2015 & 29.6 & 22.7 & 36.6 & 23.9 \\
\hline 2016 & 27.3 & 21.4 & 39.1 & 22.8 \\
\hline 2017 & 27.0 & 19.7 & 39.7 & 22.6 \\
\hline Promedio & 29.8 & 19.6 & 27.6 & 20.4 \\
\hline
\end{tabular}

Fuente: Elaboración propia con base en datos del Banco Mundial al mes de mayo (2019g), disponible en: https://datos.bancomundial.org/indicador/NE.IMP.GNFS.ZS?view=chart

De los cuatro países de la AP, Chile presenta una mayor participación del comercio exterior en su PIB, es decir si sumamos el promedio de exportaciones e importaciones (tabla 1 y 2), alcanzan el 62.7 por ciento del PIB, lo cual 
indica la alta interdependencia en el PIB relacionado con compras y ventas con el exterior, le sigue México con 53.6 por ciento de participación del comercio exterior en el PIB, después se encuentra Perú con 40.9 por ciento de las exportaciones e importaciones en el PIB, al final, Colombia con 36.1 por ciento de la participación de las compras, así como de las ventas con el exterior reflejadas en su PIB.

Conforme los datos de las tablas 1 y 2, vemos que Chile y México tienen una mayor participación del comercio exterior en su PIB, asimismo en la tabla 3 las tasas de crecimiento en el PIB son más altas en Chile, mismas que alcanzan un promedio de 1990 a 2017 de 4.7 por ciento, le sigue Perú con 4.3 por ciento, Colombia con 3.5 por ciento y México con 2.7 por ciento. Entonces México a pesar de ser el segundo mercado de la AP con mayor relación de las exportaciones e importaciones en su PIB, es el que tiene las tasas de crecimiento económico más bajas, dicha situación es resultado de su alta dependencia con el mercado de Estados Unidos, país que durante las últimas décadas tiene tasas de crecimiento bajas y en 2009 su PIB cayó en 2.8 por ciento (BM, 2019d), trayendo consigo una caída en la demanda, así como en las importaciones, ello muestra la necesidad de México para diversificar sus compras y ventas con el exterior, por ello la AP puede ser estratégica si logra que las empresas puedan vender parte de su producción en los mercados de Chile, Colombia y Perú que estimulen el crecimiento del PIB mexicano, en otras palabras que se fortalezcan los lazos económicos entre estos países.

Lo anterior pone de manifiesto una relación comercial que requiere ser fortalecida en el marco del proceso de integración en ciernes con el surgimiento de la ZLC de la AP. Ello enmarcado en el fundamento teórico del comercio internacional y de la propia teoría de la integración económica con la finalidad de generar suficientes beneficios que puedan ser orientados a la generación de conocimiento y su aplicación perfilando el incremento de la competitividad de la ZLC de la AP.

\section{Crecimiento económico e ingreso per cápita en países de la AP}

Como mencionamos, la economía de países de la AP tiene una alta dependencia del mercado exterior, porque las exportaciones e importaciones representan en el PIB de Chile el 62.7 por ciento, en México el 53.6 por ciento, en Perú el 40.9 por ciento y con Colombia el 36.1 por ciento (tabla 1 y 2). Teniendo la característica de estar altamente vinculados con las compras y ventas con 
Reflexiones sobre el proceso de integración de la Alianza del Pacífico desde la perspectiva de la competitividad e inversión en ciencia y tecnología: retos para la integración comercial futura

Tabla 3

Tasas de crecimiento económico en los países de la AP

\begin{tabular}{|c|c|c|c|c|}
\hline 1990 & 3.3 & 4.3 & 5.2 & -5.0 \\
\hline 1991 & 7.8 & 2.0 & 4.2 & 2.2 \\
\hline 1992 & 11.2 & 4.0 & 3.5 & -0.5 \\
\hline 1993 & 6.6 & 5.4 & 1.9 & 5.2 \\
\hline 1994 & 5.0 & 5.8 & 4.9 & 12.3 \\
\hline 1995 & 8.9 & 5.2 & -6.3 & 7.4 \\
\hline 1996 & 6.8 & 2.1 & 6.8 & 2.8 \\
\hline 1997 & 7.4 & 3.4 & 6.8 & 6.5 \\
\hline 1998 & 4.3 & 0.6 & 5.2 & -0.4 \\
\hline 1999 & -0.4 & -4.2 & 2.8 & 1.5 \\
\hline 2000 & 5.3 & 2.9 & 4.9 & 2.7 \\
\hline 2001 & 3.3 & 1.7 & -0.4 & 0.6 \\
\hline 2002 & 3.1 & 2.5 & 0.0 & 5.5 \\
\hline 2003 & 4.1 & 3.9 & 1.4 & 4.2 \\
\hline 2004 & 7.2 & 5.3 & 3.9 & 5.0 \\
\hline 2005 & 5.7 & 4.7 & 2.3 & 6.3 \\
\hline 2006 & 6.3 & 6.8 & 4.5 & 7.5 \\
\hline 2007 & 4.9 & 6.8 & 2.3 & 8.5 \\
\hline 2008 & 3.5 & 3.3 & 1.1 & 9.1 \\
\hline 2009 & -1.6 & 1.2 & -5.3 & 1.1 \\
\hline 2010 & 5.8 & 4.3 & 5.1 & 8.3 \\
\hline 2011 & 6.1 & 7.4 & 3.7 & 6.3 \\
\hline 2012 & 5.3 & 3.9 & 3.6 & 6.1 \\
\hline 2013 & 4.0 & 4.6 & 1.4 & 5.9 \\
\hline 2014 & 1.8 & 4.7 & 2.8 & 2.4 \\
\hline 2015 & 2.3 & 3.0 & 3.3 & 3.3 \\
\hline 2016 & 1.3 & 2.0 & 2.9 & 4.0 \\
\hline 2017 & 1.5 & 1.8 & 2.0 & 2.5 \\
\hline Promedio & 4.7 & 3.5 & 2.7 & 4.3 \\
\hline
\end{tabular}

Fuente: Elaboración propia con base en datos del Banco Mundial al mes de mayo (2019a), disponible en: https://datos.bancomundial.org/indicador/NY.GDP.MKTP.KD.ZG?view=chart 
mercados de otros países, el crecimiento de su economía y por lo tanto de su ingreso per cápita también dependerá de que sus socios comerciales tengan más exportaciones e importaciones, para que con ello, el PIB se incremente e impacte en la riqueza de la sociedad de Chile, Colombia, México y Perú, como un todo integrado.

De acuerdo con lo planteado, México, Chile, Colombia y Perú necesitan alcanzar mayores tasas de crecimiento en su PIB, con la finalidad de estimular mayor riqueza entre sus habitantes, por ello buscan aliarse con otros países por medio de la apertura y acuerdos que permitan hacer crecer su mercado, conectándose con más empresas que potencien el comercio de las exportaciones e importaciones, la competitividad, así como la innovación de procesos y bienes.

Chile, Colombia, México y Perú en sus esfuerzos por lograr un mayor crecimiento en el PIB y asimismo una diversificación de sus mercados integrados desde el año 2011 (Alianza del Pacífico, 2019b), diseñan e impulsan normas y políticas para facilitar las exportaciones e importaciones entre ellos. De esta manera, han logrado alcanzar en su breve historia, diferentes tasas de crecimiento en el PIB, las cuales en el caso de Chile y Colombia son más altas después del año 2010, por el contrario, en México y Perú sus tasas de crecimiento en el PIB descienden, situación paradójica, porque con la creación de la AP debería darse un mayor volumen de ventas y compras que impulsen el crecimiento de su PIB, lo cual muestra una desarticulación productiva de origen, que es deseable pueda ser transformada con el paso de los años.

En la tabla 4, se muestra el ritmo de crecimiento en el PIB, así como los avances logrados en el incremento de la riqueza de la población de México, Chile, Colombia y Perú, observándose que la sociedad chilena tiene un mayor nivel de crecimiento, al igual una mayor evolución en el ingreso per cápita, México a pesar de ser la nación más grande en términos económicos, es la que más se rezaga en el crecimiento del PIB y logra ubicarse después de Chile en lo correspondiente al ingreso per cápita. El ingreso de los países de la AP no es alto en el contexto de economías que tienen liberalización en sus fronteras, mostrando la existencia de mercados estrechos en relación con la capacidad de compra alcanzada y de igual forma, la expansión que pudiera tener el potencial de demanda para estimular la producción de más bienes y servicios. 
Reflexiones sobre el proceso de integración de la Alianza del Pacífico desde la perspectiva de la competitividad e inversión en ciencia y tecnología: retos para la integración comercial futura

\section{Tabla 4}

Tasas del crecimiento en el PIB y evolución del ingreso per cápita en países de la AP

\begin{tabular}{|c|c|c|c|c|c|c|c|c|}
\hline 1990 & 3.33 & 4507.1 & 4.28 & 4869.2 & 5.18 & 6037.0 & -4.98 & 3433.8 \\
\hline 1991 & 7.80 & 4947.4 & 2.00 & 5050.7 & 4.21 & 6373.4 & 2.22 & 3552.5 \\
\hline 1992 & 11.17 & 5621.1 & 4.04 & 5327.9 & 3.54 & 6621.6 & -0.54 & 3541.7 \\
\hline 1993 & 6.59 & 6123.8 & 5.39 & 5485.5 & 1.94 & 8415.5 & 5.24 & 3742.5 \\
\hline 1994 & 5.03 & 6578.5 & 5.81 & 5828.0 & 4.94 & 8892.5 & 12.31 & 4213.5 \\
\hline 1995 & 8.93 & 7366.1 & 5.20 & 6155.7 & -6.29 & 8390.3 & 7.41 & 4539.6 \\
\hline 1996 & 6.80 & 8028.9 & 2.06 & 6294.9 & 6.77 & 8677.7 & 2.80 & 4673.6 \\
\hline 1997 & 7.43 & 8655.3 & 3.43 & 6520.0 & 6.85 & 9357.3 & 6.48 & 4982.7 \\
\hline 1998 & 4.32 & 9009.3 & 0.57 & 6528.9 & 5.16 & 9797.4 & -0.39 & 4942.9 \\
\hline 1999 & -0.41 & 8995.2 & -4.20 & 6256.8 & 2.75 & 10155.5 & 1.49 & 5021.5 \\
\hline 2000 & 5.33 & 9572.0 & 2.92 & 6585.3 & 4.94 & 10799.1 & 2.69 & 5202.2 \\
\hline 2001 & 3.30 & 9994.2 & 1.68 & 6750.7 & -0.40 & 10878.9 & 0.62 & 5283.0 \\
\hline 2002 & 3.11 & 10343.2 & 2.50 & 6927.3 & -0.04 & 10901.1 & 5.45 & 5584.3 \\
\hline 2003 & 4.09 & 10858.8 & 3.92 & 7241.3 & 1.45 & 10954.5 & 4.17 & 5858.9 \\
\hline 2004 & 7.21 & 11831.3 & 5.33 & 7732.3 & 3.92 & 11506.8 & 4.96 & 6240.7 \\
\hline 2005 & 5.74 & 12774.7 & 4.71 & 8248.4 & 2.31 & 12369.8 & 6.29 & 6762.8 \\
\hline 2006 & 6.32 & 15773.8 & 6.78 & 8957.3 & 4.50 & 13437.5 & 7.53 & 7404.3 \\
\hline 2007 & 4.91 & 16971.8 & 6.85 & 9710.9 & 2.29 & 14000.0 & 8.52 & 8148.9 \\
\hline 2008 & 3.53 & 16551.3 & 3.26 & 10132.3 & 1.14 & 14551.0 & 9.13 & 8956.5 \\
\hline 2009 & -1.56 & 16226.2 & 1.21 & 10260.2 & -5.29 & 14172.5 & 1.10 & 9010.3 \\
\hline 2010 & 5.84 & 18265.3 & 4.35 & 10680.0 & 5.12 & 14858.5 & 8.33 & 9755.1 \\
\hline 2011 & 6.11 & 20437.7 & 7.36 & 11496.5 & 3.66 & 16049.4 & 6.33 & 10449.1 \\
\hline 2012 & 5.32 & 21620.3 & 3.90 & 12058.3 & 3.64 & 16658.1 & 6.14 & 11145.5 \\
\hline 2013 & 4.05 & 22578.7 & 4.57 & 12725.0 & 1.35 & 16848.0 & 5.85 & 11828.8 \\
\hline 2014 & 1.77 & 22978.2 & 4.73 & 13395.5 & 2.80 & 17481.9 & 2.38 & 12165.0 \\
\hline 2015 & 2.31 & 22785.8 & 2.96 & 13827.7 & 3.29 & 17239.3 & 3.25 & 12533.5 \\
\hline 2016 & 1.27 & 23476.4 & 1.96 & 14165.5 & 2.90 & 17769.7 & 3.95 & 13030.0 \\
\hline 2017 & 1.49 & 24085.0 & 1.79 & 14552.0 & 2.04 & 18149.1 & 2.53 & 13434.1 \\
\hline Promedio & 4.68 & 13462.76 & 3.55 & 8705.86 & 2.67 & 12190.83 & 4.33 & 7337.05 \\
\hline
\end{tabular}

Fuente: Elaboración propia con base en datos del Banco Mundial al mes de mayo (2019a;2019h), disponible en: https://datos.bancomundial.org/indicador/NY.GDP.MKTP.KD.ZG?view=chart y https://datos.bancomundial.org/indicador/NY.GNP.PCAP.PP.CD?view=chart

De acuerdo con los datos de la tabla 4, los países de la AP en promedio de 1990 a 2017, tuvieron un crecimiento en el PIB por debajo del 5 por ciento, de igual manera el ingreso per cápita fue inferior a los 14 mil dólares, lo cual refleja que es 
necesario además de un mayor crecimiento económico, mayor inversión en I\&D para contribuir al mejoramiento de procesos productivos que impulsen tanto el crecimiento del PIB, así como el ingreso per cápita de la sociedad, transformando el panorama de los mercados de trabajo y el salario, dinamizando por lo tanto, la oferta y demanda de bienes en un mercado competitivo.

Las naciones que logran en su población un ingreso per cápita alto, generan mayores condiciones de expansión de su mercado por la capacidad de compra y de consumo de bienes, así como de servicios que van fortaleciendo la producción y la competitividad del país de la mano de una mayor inversión en ciencia y tecnología para robustecer la forma de pensar y hacer en la estructura productiva que involucra a todos los actores económicos de la sociedad.

\section{Inversión en Investigación y Desarrollo en países de la AP}

La creación de ciencia y tecnología a través de la I\&D son aspectos insoslayables en un país y en el conjunto de su economía para hacer crecer el PIB e incrementar el ingreso per cápita y la competitividad en todos los sectores productivos. Países con mayores ingresos en su población y más competitivos en el mundo, invierten en I\&D más del 2 por ciento de su PIB, logrando avances en procesos y bienes consolidados en patentes, que hacen crecer la riqueza de sus habitantes, ejemplo de ello son naciones como Estados Unidos de América, Alemania, Japón, Corea del Sur, Israel, entre otros que tienen en su población ingresos per cápita por arriba de los $\$ 30,000$ (treinta mil) dólares (BM, 2019d).

Los países dependen de la innovación para lograr mayores niveles de crecimiento económico y de competitividad, entonces con la incorporación de avances en la ciencia y la tecnología en sectores productivos de la industria en naciones de la AP, tendrán mayores posibilidades para adecuar sus leyes, normas y políticas que estimulen el incremento del comercio, la inversión y la economía, mejorando los ingresos y la integración entre sus mercados.

La nueva tecnología generada influye en la vida económica, y es deseable que las leyes, normas y políticas impacten en ese adelanto, así como en la práctica se apliquen los avances tecnológicos que favorecen la competitividad, el crecimiento de la economía y de la inversión en ciencia y tecnología. Entonces los países de la AP deben poner atención en la creación de nuevas tecnologías invirtiendo más en investigación orientada a generar mayores transacciones comerciales, al igual que propiciar mejorías en su infraestructura para estimular la llegada de más IED con un alto contenido tecnológico. 
Reflexiones sobre el proceso de integración de la Alianza del Pacífico desde la perspectiva de la competitividad e inversión en ciencia y tecnología: retos para la integración comercial futura

En la tabla 5, se puede observar que los países con mayores montos de inversión en I\&D son México y Chile, alcanzando un promedio de 0.4 por ciento del PIB destinado a la creación de ciencia y tecnología, les sigue Colombia con 0.2 por ciento y al final Perú con 0.10 por ciento. Como mencionamos en el párrafo anterior los países que han logrado ingresos per cápita que superan los 30 mil dólares anuales, invierten en I\&D más del 2 por ciento de su PIB. Entonces los países de la AP están muy por debajo de lo que se debe estar haciendo e invirtiendo para lograr mayores niveles de riqueza y de competitividad de sus sociedades, y lo más complejo es que no se detecta un plan de estas naciones, para que en los próximos años se canalice más del uno por ciento del PIB a la creación de ciencia y tecnología.

Las cifras plasmadas en la tabla 5 , indican que la población de países de la AP, están lejos de ver incrementado su ingreso per cápita y de igual manera, la urgencia que tienen los gobiernos, empresas y sociedad de los cuatro países de canalizar más recursos financieros a la I\&D, para permitir a su sector productivo contar con procesos de vanguardia que coadyuven al incremento de la oferta, y de igual manera su población alcance mayores ingresos que contribuyan al incremento de la demanda, impulsando una mayor integración en los mercados por medio de un mayor consumo que se refleje en el volumen comercial y de inversiones, producto de la creación de ciencia y tecnología favoreciendo la competitividad.

Como mencionamos existen pocos recursos canalizados a la I\&D de la AP, lo cual afecta la economía y el ingreso per cápita e impacta en una mayor competitividad integradora. Al presentarse cantidades bajas del PIB destinadas a la creación de ciencia y tecnología, se observa un impacto en el número de investigadores.

En la tabla 6, se muestra que ninguno de los países de la AP se acerca a los 500 investigadores por millón de habitantes, Chile es el país que tiene más personas trabajando en la creación de ciencia y tecnología con 376 investigadores por cada millón de habitantes, le sigue México con 286 investigadores, después Colombia con 124 personas que se dedican a la investigación y desarrollo, en el caso de Perú no se dispone de datos en la base que tiene el Banco Mundial. Es preocupante ver dichas cifras, porque las naciones con más competitividad e ingresos altos en su población cuentan con más de 4,000 personas que están creando la ciencia y la tecnología que fortalece su economía, sus ingresos y la competitividad de sus sectores productivos. 
Tabla 5

Porcentaje del PIB que se invierte en I\&D en países de la AP

\begin{tabular}{|c|c|c|c|c|}
\hline 1996 & ND & 0.3 & 0.3 & ND \\
\hline 1997 & ND & 0.3 & 0.3 & 0.1 \\
\hline 1998 & ND & ND & 0.3 & 0.1 \\
\hline 1999 & ND & ND & 0.3 & 0.1 \\
\hline 2000 & $\mathrm{ND}$ & 0.1 & 0.3 & 0.1 \\
\hline 2001 & ND & 0.1 & 0.3 & 0.1 \\
\hline 2002 & ND & 0.1 & 0.4 & 0.1 \\
\hline 2003 & ND & 0.2 & 0.4 & 0.1 \\
\hline 2004 & ND & 0.2 & 0.4 & 0.2 \\
\hline 2005 & ND & 0.1 & 0.4 & $\mathrm{ND}$ \\
\hline 2006 & ND & 0.1 & 0.4 & ND \\
\hline 2007 & 0.3 & 0.2 & 0.4 & ND \\
\hline 2008 & 0.4 & 0.2 & 0.5 & $\mathrm{ND}$ \\
\hline 2009 & 0.4 & 0.2 & 0.5 & ND \\
\hline 2010 & 0.3 & 0.2 & 0.5 & ND \\
\hline 2011 & 0.4 & 0.2 & 0.5 & 0.1 \\
\hline 2012 & 0.4 & 0.2 & 0.5 & 0.1 \\
\hline 2013 & 0.4 & 0.3 & 0.5 & 0.1 \\
\hline 2014 & 0.4 & 0.3 & 0.5 & 0.1 \\
\hline 2015 & 0.4 & 0.3 & 0.5 & 0.1 \\
\hline 2016 & 0.4 & 0.3 & 0.5 & 0.1 \\
\hline 2017 & ND & 0.2 & ND & 0.1 \\
\hline Promedio & 0.4 & 0.2 & 0.4 & 0.1 \\
\hline
\end{tabular}

Nota: ND= No Disponible

Fuente: Elaboración propia con base en datos del Banco Mundial al mes de mayo (2019f), disponible en: https://datos.bancomundial.org/indicador/GB.XPD.RSDV.GD.ZS?view=chart 
Reflexiones sobre el proceso de integración de la Alianza del Pacífico desde la perspectiva de la competitividad e inversión en ciencia y tecnología: retos para la integración comercial futura

\section{Tabla 6}

Investigadores que se dedican a la creación de ciencia y tecnología por millón de habitantes en los países de la AP

\begin{tabular}{|c|c|c|c|c|}
\hline Año & Chile & Colombia & México & Perú \\
\hline 1996 & ND & 70.1 & 206.8 & ND \\
\hline 1997 & ND & 74.2 & 218.7 & $\mathrm{ND}$ \\
\hline 1998 & ND & ND & 209.1 & ND \\
\hline 1999 & ND & ND & 216.1 & ND \\
\hline 2000 & ND & 99.3 & 216.2 & ND \\
\hline 2001 & ND & 111.2 & 224.4 & $\mathrm{ND}$ \\
\hline 2002 & ND & 126.8 & 294.8 & ND \\
\hline 2003 & ND & 138.3 & 313.9 & ND \\
\hline 2004 & ND & 110.4 & 366.9 & $\mathrm{ND}$ \\
\hline 2005 & ND & 121.6 & 400.2 & ND \\
\hline 2006 & ND & 137.3 & 325.5 & $\mathrm{ND}$ \\
\hline 2007 & 337.2 & 153.7 & 335.3 & ND \\
\hline 2008 & 357.9 & 166.8 & 327.4 & ND \\
\hline 2009 & 288.7 & 172.0 & 367.8 & ND \\
\hline 2010 & 319.7 & 182.3 & 324.5 & ND \\
\hline 2011 & 353.4 & 168.0 & 330.8 & ND \\
\hline 2012 & 390.9 & 146.0 & 238.3 & $\mathrm{ND}$ \\
\hline 2013 & 335.3 & 115.9 & 241.8 & ND \\
\hline 2014 & 427.0 & 114.8 & ND & $\mathrm{ND}$ \\
\hline 2015 & 455.5 & 68.5 & ND & ND \\
\hline 2016 & 502.1 & 88.5 & ND & ND \\
\hline 2017 & ND & ND & ND & ND \\
\hline 2018 & ND & ND & ND & ND \\
\hline Promedio & 376.8 & 124.5 & 286.6 & ND \\
\hline
\end{tabular}

Nota: ND= No Disponible

Fuente: Elaboración propia con base en datos del Banco Mundial 2018 y 2019 (BM, 2019i), disponible en: https://datos.bancomundial.org/indicador/SP.POP.SCIE.RD.P6?view=chart

Los datos de la tabla 6, reflejan la dificultad que tienen los países de la AP para logar una verdadera integración que impulse y logre robustecer sus economías, porque al contar con pocos investigadores que estén creando la ciencia y la tecnología, conforme a las necesidades sociales del país, así como de su estructura productiva, muestran que no tendrán la capacidad de convertirse en economías complementarias que cimienten las bases para hacer 
crecer su PIB, al igual que los ingresos per cápita, así como consolidar pilares de la competitividad que dinamicen sus mercados en la oferta y demanda de bienes y servicios. Si sumamos a lo mencionado que los países de la AP no se acercan al uno por ciento del PIB en inversión en I\&D, dicha situación parece los estará perpetuando en una dependencia tecnológica, y alejándolos del top ten de los niveles de competitividad.

\section{Posición de los países de la AP en los pilares de la competitividad}

Como se ha mencionado, la competitividad se mide en doce pilares. En la tabla 7 , se muestra que las cuatro economías de la AP tienen una posición, donde el mejor posicionado es Chile que se ubica entre los cuarenta países más competitivos, le sigue México entre los sesenta países con mayor competitividad, después Colombia y Perú que se encuentran entre las setenta economías más competitivas (WEF, 2019).

Conforme la evaluación realizada por el WEF en los doce pilares que sostienen la competitividad, se detecta en la tabla 7, que tanto Chile, Colombia, México y Perú, requieren trabajar intensa y sistemáticamente para lograr que sus instituciones trasmitan claridad y certidumbre con sus normas y políticas implementadas, y de igual manera que a través de estas se den las condiciones de establecer y crear la infraestructura necesaria para impactar positivamente en el ambiente macroeconómico, en la salud y la educación básica, así como en la educación superior y capacitación, al igual que en la eficiencia de los mercados de bienes, laboral y financiero, la preparación tecnológica, tamaño de mercado, sofisticación empresarial e innovación tecnológica.

Los resultados de la evaluación en el pilar de la innovación, indica que México se encuentra en la posición 56, Chile en la 52, Colombia en la 73 y Perú en la 113, siendo que en el año 2010 habían tenido una mejor posición, Chile que alcanzó el lugar 49, Colombia el 63 y Perú el 109, en el caso de México tenía una posición más baja estando ubicado en la posición 78, ello como resultado de una mayor inversión en I\&D comparado con lo que hace el resto de países de la AP, pero por debajo de lo que invierten los países más competitivos, con cifras que superar (WEF, 2019).

Si los procesos de innovación tecnológica de los países de la AP, continúan con evaluaciones bajas y los montos de inversión del PIB destinados a la creación de ciencia y tecnología continúan por debajo del uno por ciento, la capacidad de sus propios mercados limitará la integración per se de los cuatro 
Reflexiones sobre el proceso de integración de la Alianza del Pacífico desde la perspectiva de la competitividad e inversión en ciencia y tecnología: retos para la integración comercial futura

Tabla 7

Pilares de la competitividad en los países de la AP

\begin{tabular}{l|c|c|c|c|c|c|c|c|c|c|c|c|c|c|c|c}
\hline Instituciones & 102 & 28 & 111 & 118 & 109 & 32 & 114 & 116 & 116 & 35 & 112 & 106 & 123 & 35 & 117 & 116 \\
\hline Infraestructura & 65 & 49 & 84 & 88 & 59 & 45 & 84 & 89 & 57 & 44 & 84 & 89 & 62 & 41 & 87 & 86 \\
\hline $\begin{array}{l}\text { Ambiente } \\
\text { macroeconómico }\end{array}$ & 53 & 22 & 29 & 21 & 56 & 29 & 32 & 23 & 51 & 32 & 53 & 33 & 43 & 36 & 62 & 37 \\
\hline $\begin{array}{l}\text { Salud y } \\
\text { educación básica }\end{array}$ & 71 & 70 & 105 & 94 & 71 & 74 & 97 & 100 & 74 & 71 & 90 & 98 & 76 & 66 & 88 & 93 \\
\hline $\begin{array}{l}\text { Educación } \\
\text { superior y } \\
\text { capacitación }\end{array}$ & 87 & 32 & 69 & 83 & 86 & 33 & 70 & 82 & 82 & 28 & 70 & 80 & 80 & 26 & 66 & 81 \\
\hline $\begin{array}{l}\text { Eficiencia en } \\
\text { mercados de } \\
\text { bienes }\end{array}$ & 86 & 34 & 109 & 53 & 82 & 40 & 108 & 60 & 70 & 44 & 100 & 65 & 70 & 39 & 102 & 75 \\
\hline $\begin{array}{l}\text { Eficiencia en } \\
\text { mercado laboral }\end{array}$ & 121 & 50 & 84 & 51 & 114 & 63 & 86 & 64 & 105 & 52 & 81 & 61 & 105 & 49 & 88 & 64 \\
\hline $\begin{array}{l}\text { Desarrollo } \\
\text { de mercado } \\
\text { financiero }\end{array}$ & 63 & 19 & 70 & 40 & 46 & 21 & 25 & 30 & 35 & 23 & 25 & 26 & 36 & 17 & 27 & 35 \\
\hline $\begin{array}{l}\text { Preparación } \\
\text { tecnológica }\end{array}$ & 79 & 42 & 68 & 92 & 73 & 39 & 70 & 88 & 73 & 39 & 64 & 88 & 71 & 38 & 65 & 86 \\
\hline $\begin{array}{l}\text { Tamaño de } \\
\text { mercado }\end{array}$ & 10 & 41 & 32 & 43 & 11 & 44 & 36 & 48 & 11 & 44 & 35 & 48 & 11 & 44 & 37 & 48 \\
\hline $\begin{array}{l}\text { Sofisticación } \\
\text { empresarial }\end{array}$ & 58 & 55 & 62 & 72 & 50 & 53 & 59 & 81 & 45 & 56 & 59 & 78 & 49 & 50 & 64 & 80 \\
\hline \begin{tabular}{l} 
Innovación \\
\hline
\end{tabular} & 61 & 48 & 77 & 117 & 59 & 50 & 76 & 116 & 55 & 63 & 79 & 119 & 56 & 52 & 73 & 113 \\
\hline
\end{tabular}

Nota: $\mathrm{M}=$ México; $\mathrm{Ch}=\mathrm{Chile} ; \mathrm{C}=$ Colombia; $\mathrm{P}=$ Perú

Fuente: Elaboración propia con base en datos del World Economic Forum (2019), disponible en: https://www.weforum.org/reports

países, que en lugar de ser economías complementarias y detonadoras de mayor producción, serán competitivas entre los bienes y servicios que producen, limitando con ello el crecimiento del comercio, la economía, así como el ingreso per cápita de la sociedad que de por sí es muy bajo (Arredondo, Vázquez, \& de la Garza, 2016).

También los países de la AP, deben tener presente que el comercio exterior en el caso de Chile y México representa más del 50 por ciento en su PIB, en lo que respecta a Colombia y Perú es menor al 50 por ciento. Entonces si la conforma- 
ción de la AP pretende una mayor integración de las economías, ésta tiene que verse reflejada en un crecimiento de las transacciones comerciales entre estos.

Desafortunadamente el comercio entre los países de la AP no representa un porcentaje significativo en cada una de las economías, por ejemplo el comercio de México representó con Chile en 2018 el 0.41 por cierto y en 2011 era de 0.60 por ciento, situación similar se observa con Colombia que en el 2018 fue de 0.60 por ciento y en 2011 de $0.92 \%$ por ciento, con Perú en 2018 alcanzó el 0.24 por ciento, mientras en 2011 había sido de 0.27 por ciento del comercio total de México con el mundo. Misma situación se detecta en la IED que sumando la entrada de capitales de Chile, Colombia y Perú no llega al 2 por ciento del total de inversión captada por la economía mexicana. Dicha información trae consigo oportunidades para que estos cuatro mercados trabajen más estrechamente en una suerte de especialización, impulsando las transacciones comerciales y con ello que más empresas inviertan en sus territorios para ir ganando presencia competitiva en sus economías con los productos al igual que los servicios generados.

\section{Comercio e Inversión Extranjera Directa en México de los países de la AP}

Tal como se ha mencionado, la integración de las economías se logra alcanzando entre otros aspectos, un crecimiento en las exportaciones e importaciones que fortalece el comercio exterior de cada uno de los países de la AP. El comercio de Chile, Colombia y Perú, así como las inversiones directas presentan un crecimiento en México después de la creación de la AP en 2011, pero dichos montos no llegan ni al uno por ciento de las exportaciones e importaciones relacionadas con el comercio total que México lleva a cabo con otros países del mundo, de igual manera, la inversión recibida procedente de los países de la AP es menor al uno por ciento del total de la IED (tablas, 8, 9, 10 y 11).

Conforme a los planteamientos de la teoría neoinstitucional y del comercio internacional, si las naciones tienen acuerdos comerciales, en este caso por medio de procesos de integración económica, debe presentarse un incremento en las transacciones comerciales, pero en el caso de México con los países de la AP se observa que el valor del comercio disminuye tanto con Chile y con Colombia, sólo crece con Perú, pero en cifras no muy significativas conforme a lo que México vende y compra con el exterior. Dicha situación consideramos obedece a los bajos montos de inversión en I\&D, así como a 
los pocos recursos humanos que se dedican a crear la ciencia y la tecnología que afecta la competitividad de los cuatro países de la AP, y de igual manera no impulsan la transformación de procesos y bienes que afectan la dinámica deseable de especialización en su integración económica.

La tabla 8 muestra que en el año 2011, el comercio total de México con Chile sumó 4 mil 173 millones de dólares, con Colombia 6 mil 457 millones de dólares y con Perú mil 868 millones de dólares. Para 2012 con Chile disminuyó el valor del comercio en 419 millones de dólares, al pasar de 4 mil 173 millones a 3 mil 754 millones de dólares, con Colombia al primer año de la creación de la AP el valor del comercio aumentó en 12 millones de dólares, al pasar de 6 mil 457 millones de dólares en 2011 a 6 mil 469 millones de dólares en 2012, y con Perú en 99 millones de dólares al pasar de mil 868 en 2011 a mil 967 en 2012. Después del año 2012 el valor del comercio disminuyó tanto con Chile y Colombia, sólo con Perú se detecta que el valor comercial creció hasta el año 2018. (SE, 2019a).

De igual manera la tabla 8, muestra que el saldo en la balanza comercial para México es positivo con Chile a partir del 2011, con Colombia y Perú a lo largo de los años se tienen más ventas que compras, lo cual trae consigo una balanza comercial favorable para México dado que se tiene un valor más alto en las exportaciones con relación al valor de lo que se importa de Chile, Colombia y Perú.

Como se ha mencionado, las ventas que realiza México con los países de la AP son mayores a las compras. De igual manera conforme a los datos de las tablas 8,9 y 10, se muestra que el comercio de Chile y Colombia con México disminuye conforme se presenta la conformación de la AP. Dicha situación refleja que las economías de estos países no están logrando integrarse para impactar positivamente en el crecimiento del comercio, si sumamos a ello que el comercio de México con los países de la AP sólo representó con Chile en 2017 el 0.40 por cierto y en 2011 era de 0.60 por ciento, es decir la participación de los países de la AP en el comercio con México disminuyó, misma situación se observa con Colombia que en 2017 fue de 0.58 por ciento y en 2011 de 0.92\% por ciento, con Perú en 2017 alcanzó el 0.24 por ciento, mientras en 2011 había sido de 0.27 por ciento del comercio total de México con el mundo (tabla 10) (SE, 2019a).

Lo anterior obedece a la propia dinámica del comercio tanto de exportaciones e importaciones que realizan los integrantes de la AP, fuera de un contexto de integración que permita la complementariedad, lo cual presenta 
retos que les permitan lograr una especificación más allá de la diversificación que implica la reconformación de los mercados globales, en cuanto los productos que se compran y se venden en los mercados internacionales, porque las transacciones comerciales realizadas, se refieren a bienes que los convierten en naciones competitivas entre sí mas no complementarias.

Sumando el comercio con Chile, Colombia y Perú no alcanzan el 2 por ciento del comercio total de México, mostrando la fragilidad para lograr una mayor integración, asimismo si se suma que en los cuatro países existe una inversión en I\&D por debajo del uno por ciento del PIB, además de encontrarse en peldaños bajos de los pilares de la competitividad. Entonces su integración comercial se encuentra en riesgo de prosperar si no existe un mayor compromiso con la creación de ciencia y tecnología que transforme procesos y bienes que dinamicen las transacciones comerciales, que impulsen el crecimiento del PIB al igual que del ingreso per cápita.

De acuerdo con lo argumentado en este escrito, el bajo dinamismo de exportaciones e importaciones de Chile, Colombia y Perú con México refleja la necesidad de continuar diseñando políticas comerciales de apertura y de eliminación de aranceles, en una base complementaria, porque si no lo hacen pueden frenar el poco comercio que existe de la AP a siete años de haberse constituido y es urgente que las transacciones comerciales crezcan y tengan un impacto positivo en la competitividad, así como en el PIB e ingreso per cápita.

Si se recuerda, los países de la AP tienen un ingreso per cápita inferior a los 14 mil dólares, situación que los convierte en naciones proveedoras de mano de obra barata, además porque los productos que exportan e importan los lleva a ser economías competidoras entre sí en lugar de conformarse como economías complementarias detonadoras del crecimiento del comercio. Otro aspecto a destacar es la concentración del comercio con Estados Unidos y China, naciones con grandes empresas que se mueven por diferentes lugares en la búsqueda de costos más bajos de producción, y asimismo conseguir la materia prima que coadyuve a tener empresas cada vez más competitivas, con una cadena de producción que engloba las tareas más repetitivas en los mercados de países en desarrollo, situación que coloca a los países de la AP frente a un área de oportunidad a superar. 
Reflexiones sobre el proceso de integración de la Alianza del Pacífico desde la perspectiva de la competitividad e inversión en ciencia y tecnología: retos para la integración comercial futura

\section{Tabla 8}

Comercio total de México y saldo de la balanza comercial de México con Chile, Colombia y Perú (miles de dólares)

\begin{tabular}{|c|c|c|c|c|c|c|}
\hline Año & $\begin{array}{l}\text { Comercio } \\
\text { total con } \\
\text { Chile }\end{array}$ & $\begin{array}{c}\text { Saldo } \\
\text { comercial } \\
\text { con Chile }\end{array}$ & $\begin{array}{l}\text { Comercio } \\
\text { total con } \\
\text { Colombia }\end{array}$ & $\begin{array}{c}\text { Saldo } \\
\text { comercial con } \\
\text { Colombia }\end{array}$ & $\begin{array}{l}\text { Comercio } \\
\text { total con } \\
\text { Perú }\end{array}$ & $\begin{array}{c}\text { Saldo } \\
\text { comercial } \\
\text { con Perú }\end{array}$ \\
\hline 1993 & 329,851 & 69,649 & 322,977 & 155,001 & 263,975 & $-75,913$ \\
\hline 1994 & 434,426 & $-25,728$ & 427,045 & 184,967 & 321,332 & $-100,498$ \\
\hline 1995 & 644,009 & 335,489 & 550,905 & 355,999 & 277,579 & 80,125 \\
\hline 1996 & 859,418 & 517,896 & 535,189 & 341,155 & 328,007 & 94,713 \\
\hline 1997 & $1,214,828$ & 470,068 & 637,567 & 389,099 & 380,021 & 96,865 \\
\hline 1998 & $1,176,992$ & 73,096 & 600,354 & 297,738 & 338,546 & 52,738 \\
\hline 1999 & $1,049,897$ & $-317,025$ & 588,014 & 147,270 & 358,601 & $-2,483$ \\
\hline 2000 & $1,325,068$ & $-462,376$ & 735,209 & 188,373 & 386,642 & 33,302 \\
\hline 2001 & $1,349,402$ & $-600,566$ & 850,731 & 161,933 & 313,907 & 31,441 \\
\hline 2002 & $1,332,708$ & $-687,754$ & $1,010,476$ & 305,616 & 385,387 & 80,801 \\
\hline 2003 & $1,463,044$ & $-700,672$ & $1,068,093$ & 256,801 & 324,972 & 62,626 \\
\hline 2004 & $1,906,702$ & $-1,020,940$ & $1,424,088$ & 153,400 & 532,046 & $-32,330$ \\
\hline 2005 & $2,421,775$ & $-1,086,455$ & $2,223,391$ & 873,143 & 790,392 & $-100,314$ \\
\hline 2006 & $3,374,684$ & $-1,564,830$ & $2,876,332$ & $1,387,892$ & $1,003,631$ & 63,293 \\
\hline 2007 & $3,764,331$ & $-1,423,591$ & $3,707,268$ & $2,179,196$ & $1,059,583$ & 293,617 \\
\hline 2008 & $4,179,190$ & $-1,005,376$ & $4,103,972$ & $1,960,892$ & $1,606,049$ & 753,575 \\
\hline 2009 & $2,699,883$ & $-601,209$ & $3,109,612$ & $1,871,468$ & 941,301 & 230,579 \\
\hline 2010 & $3,815,769$ & $-88,877$ & $4,552,471$ & $2,961,801$ & $1,310,712$ & 636,458 \\
\hline 2011 & $4,173,412$ & $-29,352$ & $6,457,144$ & $4,808,132$ & $1,868,741$ & 704,047 \\
\hline 2012 & $3,754,114$ & 748,898 & $6,469,325$ & $4,715,195$ & $1,967,612$ & $1,087,678$ \\
\hline 2013 & $3,523,091$ & 646,243 & $5,646,932$ & $3,823,408$ & $2,355,835$ & $1,185,145$ \\
\hline 2014 & $3,545,600$ & 750,404 & $5,668,365$ & $3,799,417$ & $2,836,437$ & 623,911 \\
\hline 2015 & $3,341,755$ & 380,949 & $4,590,543$ & $2,745,547$ & $2,332,135$ & 969,501 \\
\hline 2016 & $3,080,447$ & 409,559 & $4,164,372$ & $1,968,632$ & $1,960,264$ & 847,666 \\
\hline 2017 & $3,340,782$ & 267,500 & $4,838,168$ & $1,489,522$ & $2,024,319$ & 997,169 \\
\hline 2018/1 & $3,474,838$ & 347,736 & $5,022,149$ & $1,640,771$ & $1,981,950$ & $1,097,230$ \\
\hline
\end{tabular}

Nota: 1 Las cifras están sujetas a cambio de acuerdo con la información de la Secretaría de Economía

Fuente: Secretaría de Economía al mes de mayo de (2019a), disponible en: http://www. economia-snci.gob.mx/sic_php/pages/estadisticas/ 


\section{Tabla 9}

Valor de las exportaciones e importaciones que realiza México con Chile, Colombia y Perú (miles de dólares)

\begin{tabular}{|c|c|c|c|c|c|c|}
\hline Año & 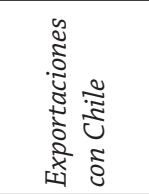 & 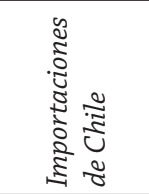 & 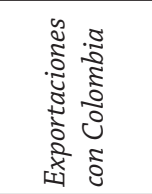 &  & 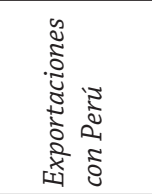 & 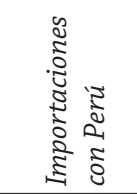 \\
\hline 1993 & 199,750 & 130,101 & 238,989 & 83,988 & 94,031 & 169,944 \\
\hline 1994 & 204,349 & 230,077 & 306,006 & 121,039 & 110,417 & 210,915 \\
\hline 1995 & 489,749 & 154,260 & 453,452 & 97,453 & 178,852 & 98,727 \\
\hline 1996 & 688,657 & 170,761 & 438,172 & 97,017 & 211,360 & 116,647 \\
\hline 1997 & 842,448 & 372,380 & 513,333 & 124,234 & 238,443 & 141,578 \\
\hline 1998 & 625,044 & 551,948 & 449,046 & 151,308 & 195,642 & 142,904 \\
\hline 1999 & 366,436 & 683,461 & 367,642 & 220,372 & 178,059 & 180,542 \\
\hline 2000 & 431,346 & 893,722 & 461,791 & 273,418 & 209,972 & 176,670 \\
\hline 2001 & 374,418 & 974,984 & 506,332 & 344,399 & 172,674 & 141,233 \\
\hline 2002 & 322,477 & $1,010,231$ & 658,046 & 352,430 & 233,094 & 152,293 \\
\hline 2003 & 381,186 & $1,081,858$ & 662,447 & 405,646 & 193,799 & 131,173 \\
\hline 2004 & 442,881 & $1,463,821$ & 788,744 & 635,344 & 249,858 & 282,188 \\
\hline 2005 & 667,660 & $1,754,115$ & $1,548,267$ & 675,124 & 345,039 & 445,353 \\
\hline 2006 & 904,927 & $2,469,757$ & $2,132,112$ & 744,220 & 533,462 & 470,169 \\
\hline 2007 & $1,170,370$ & $2,593,961$ & $2,943,232$ & 764,036 & 676,600 & 382,983 \\
\hline 2008 & $1,586,907$ & $2,592,283$ & $3,032,432$ & $1,071,540$ & $1,179,812$ & 426,237 \\
\hline 2009 & $1,049,337$ & $1,650,546$ & $2,490,540$ & 619,072 & 585,940 & 355,361 \\
\hline 2010 & $1,863,446$ & $1,952,323$ & $3,757,136$ & 795,335 & 973,585 & 337,127 \\
\hline 2011 & $2,072,030$ & $2,101,382$ & $5,632,638$ & 824,506 & $1,286,394$ & 582,347 \\
\hline 2012 & $2,251,506$ & $1,502,608$ & $5,592,260$ & 877,065 & $1,527,645$ & 439,967 \\
\hline 2013 & $2,084,667$ & $1,438,424$ & $4,735,170$ & 911,762 & $1,770,490$ & 585,345 \\
\hline 2014 & $2,148,002$ & $1,397,598$ & $4,733,891$ & 934,474 & $1,730,174$ & $1,106,263$ \\
\hline 2015 & $1,861,352$ & $1,480,403$ & $3,668,045$ & 922,498 & $1,650,818$ & 681,317 \\
\hline 2016 & $1,745,003$ & $1,335,444$ & $3,066,502$ & $1,097,870$ & $1,403,965$ & 556,299 \\
\hline 2017 & $1,536,641$ & $3,340,782$ & $3,163,845$ & $1,674,323$ & $1,510,744$ & 513,575 \\
\hline $2018 / 1$ & $1,911,287$ & $1,563,551$ & $3,331,460$ & $1,690,689$ & $1,539,590$ & 442,360 \\
\hline
\end{tabular}

Nota: 1 Las cifras están sujetas a cambio de acuerdo con la información de la Secretaría de Economía

Fuente: Secretaría de Economía al mes de mayo (2019a), disponible en: http://www. economia-snci.gob.mx/sic_php/pages/estadisticas/

Como se mencionó, el saldo del valor de las exportaciones e importaciones es favorable para México, pero ello no indica un porcentaje relevante dado el tamaño de la economía (tabla 10). Dicha situación debe obligar al diseño 
de estrategias que permitan a las empresas mexicanas incursionar con más y diferentes productos en los mercados de la AP, de igual manera por ser el mercado más grande de los cuatro, generar bases que realmente les permita consolidar la integración económica, lo cual requerirá de un trabajo estratégico y sistemático para transitar de ZLC, a una integración de acuerdo con lo establecido por la teoría.

Al igual que la baja participación de las exportaciones e importaciones se tiene que la IED de los países miembros de la AP no es significativa, ello porque sumando los montos de Chile, Colombia y Perú en el año 2018 no llega a un porcentaje representativo. Por ejemplo, la inversión que recibió México desde Chile en 2011 fue del 0.25 por ciento, misma que alcanzó el 0.28 por ciento para 2018; desde Colombia, en los mismos años, fue de 1.22 por ciento y de menos 0.01 por ciento respectivamente; desde Perú 0.02 por ciento y 0.05 por ciento, (tabla 11).

Es decir, con los tres países la proporción de la participación de la IED en México con sus socios de la AP no muestra un aprovechamiento real que estimule la llegada de capitales y de mercancías entre los cuatro países para lograr integrar sus economías por medio de un mayor impulso, tanto del comercio como de la inversión según lo sugiere el objetivo de creación de la AP.

La poca participación de la IED directa de países de la AP en México, también es un reflejo de los bajos montos canalizados a la inversión en I\&D, pues los que más invierten son Chile y México con un 0.4 por ciento del PIB. Dichos montos no contribuyen para que estas naciones vayan ganando presencia con sus exportaciones en la generación de productos de alto valor agregado que generen complementariedad y no competitividad en sus sectores productivos.

\section{Reflexiones finales}

Los países de la AP, muestran la intención de fortalecer mercados integrados del lado del Pacífico Latinoamericano frente al Asia Pacífico, que se presenta en el Siglo XXI, como la región económica más dinámica del mundo. Entendida como ZLC, la AP es tan solo el inicio de un proceso que tiende a integrar mayormente una región articulada por su pasado común, dueña de condiciones específicas y similares, como el idioma y su propia historia.

Esta iniciativa de la AP se encuentra con escasos vínculos comerciales de exportaciones e importaciones entre sí, en comparación con la dinámica económica que presentan otras regiones y subregiones económicas del mun- 
Tabla 10

Comercio total y participación en el comercio de México de los países de Chile, Colombia y Perú (miles de dólares y porcentaje)

\begin{tabular}{|c|c|c|c|c|c|c|}
\hline 1993 & 329,851 & 0.28 & 322,977 & 0.28 & 263,975 & 0.23 \\
\hline 1994 & 434,426 & 0.31 & 427,045 & 0.30 & 321,332 & 0.23 \\
\hline 1995 & 644,009 & 0.42 & 550,905 & 0.36 & 277,579 & 0.18 \\
\hline 1996 & 859,418 & 0.46 & 535,189 & 0.29 & 328,007 & 0.18 \\
\hline 1997 & $1,214,828$ & 0.55 & 637,567 & 0.29 & 380,021 & 0.17 \\
\hline 1998 & $1,176,992$ & 0.48 & 600,354 & 0.25 & 338,546 & 0.14 \\
\hline 1999 & $1,049,897$ & 0.38 & 588,014 & 0.21 & 358,601 & 0.13 \\
\hline 2000 & $1,325,068$ & 0.39 & 735,209 & 0.22 & 386,642 & 0.11 \\
\hline 2001 & $1,349,402$ & 0.41 & 850,731 & 0.26 & 313,907 & 0.10 \\
\hline 2002 & $1,332,708$ & 0.40 & $1,010,476$ & 0.31 & 385,387 & 0.12 \\
\hline 2003 & $1,463,044$ & 0.44 & $1,068,093$ & 0.32 & 324,972 & 0.10 \\
\hline 2004 & $1,906,702$ & 0.50 & $1,424,088$ & 0.37 & 532,046 & 0.14 \\
\hline 2005 & $2,421,775$ & 0.56 & $2,223,391$ & 0.51 & 790,392 & 0.18 \\
\hline 2006 & $3,374,684$ & 0.67 & $2,876,332$ & 0.57 & $1,003,631$ & 0.20 \\
\hline 2007 & $3,764,331$ & 0.68 & $3,707,268$ & 0.67 & $1,059,583$ & 0.19 \\
\hline 2008 & $4,179,190$ & 0.70 & $4,103,972$ & 0.68 & $1,606,049$ & 0.27 \\
\hline 2009 & $2,699,883$ & 0.58 & $3,109,612$ & 0.67 & 941,301 & 0.20 \\
\hline 2010 & $3,815,769$ & 0.64 & $4,552,471$ & 0.76 & $1,310,712$ & 0.22 \\
\hline 2011 & $4,173,412$ & 0.60 & $6,457,144$ & 0.92 & $1,868,741$ & 0.27 \\
\hline 2012 & $3,754,114$ & 0.51 & $6,469,325$ & 0.87 & $1,967,612$ & 0.27 \\
\hline 2013 & $3,523,091$ & 0.46 & $5,646,932$ & 0.74 & $2,355,835$ & 0.31 \\
\hline 2014 & $3,545,600$ & 0.44 & $5,668,365$ & 0.71 & $2,836,437$ & 0.36 \\
\hline 2015 & $3,341,755$ & 0.43 & $4,590,543$ & 0.59 & $2,332,135$ & 0.30 \\
\hline 2016 & $3,080,447$ & 0.40 & $4,164,372$ & 0.55 & $1,960,264$ & 0.26 \\
\hline 2017 & $3,340,782$ & 0.40 & $4,838,168$ & 0.58 & $2,024,319$ & 0.24 \\
\hline $2018 / 1$ & $3,474,838$ & 0.41 & $5,022,149$ & 0.60 & $1,981,950$ & 0.24 \\
\hline
\end{tabular}

Nota: 1 Las cifras están sujetas a cambio de acuerdo con la información de la Secretaría de Economía

Fuente: Elaboración propia con base en datos de la Secretaría de Economía al mes de mayo (2019a), disponible en: http://www.economia-snci.gob.mx/sic_php/pages/estadisticas/ 
Reflexiones sobre el proceso de integración de la Alianza del Pacífico desde la perspectiva de la competitividad e inversión en ciencia y tecnología: retos para la integración comercial futura

Tabla 11

Flujos de IED de los países de Chile, Colombia y Perú en México (millones de dólares)

\begin{tabular}{l|r|r|r|r|r|r|c}
\hline Año & $\begin{array}{c}\text { IED Total } \\
\text { en México }\end{array}$ & Chile & $\begin{array}{c}\text { Participación } \\
\text { IED Chile en } \\
\text { México }\end{array}$ & Colombia & $\begin{array}{c}\text { Participación } \\
\text { IED Colombia } \\
\text { en México }\end{array}$ & Perú & $\begin{array}{c}\text { Participación } \\
\text { IED Perú en } \\
\text { México }\end{array}$ \\
\hline 1999 & $13,943.6$ & 6.3 & 0.045 & -3.0 & -0.022 & 0.6 & 0.004 \\
\hline 2000 & $18,247.1$ & 4.5 & 0.025 & 12.0 & 0.066 & 3.0 & 0.016 \\
\hline 2001 & $30,041.8$ & 11.0 & 0.037 & 7.0 & 0.023 & 1.1 & 0.003 \\
\hline 2002 & $24,055.3$ & 35.2 & 0.146 & 22.5 & 0.094 & 1.2 & 0.005 \\
\hline 2003 & $18,225.1$ & 16.5 & 0.091 & 9.3 & 0.051 & -0.7 & -0.004 \\
\hline 2004 & $24,916.4$ & 37.7 & 0.151 & 34.7 & 0.139 & 13.2 & 0.052 \\
\hline 2005 & $26,023.1$ & 38.8 & 0.149 & 26.9 & 0.103 & 0.5 & 0.001 \\
\hline 2007 & $21,098.1$ & 60.8 & 0.288 & 21.3 & 0.101 & 0.5 & 0.002 \\
\hline 2008 & $29,420.0$ & 33.6 & 0.114 & 48.7 & 0.166 & 104.1 & 0.353 \\
\hline 2009 & $18,165.2$ & 52.9 & 0.291 & 47.1 & 0.259 & -1.8 & -0.009 \\
\hline 2010 & $27,319.0$ & 86.9 & 0.318 & 63.5 & 0.233 & -2.6 & -0.009 \\
\hline 2011 & $25,221.4$ & 63.6 & 0.252 & 308.9 & 1.225 & 7.1 & 0.028 \\
\hline 2013 & $21,730.3$ & 28.2 & 0.130 & 61.0 & 0.281 & 8.0 & 0.036 \\
\hline 2014 & $48,491.7$ & 113.0 & 0.233 & 78.3 & 0.162 & 4.7 & 0.009 \\
\hline 2015 & $28,672.0$ & 72.2 & 0.252 & 59.4 & 0.207 & 15.1 & 0.052 \\
\hline 2016 & $29,7557.6$ & 125.9 & 0.361 & 95.6 & 0.274 & 2.9 & 0.008 \\
\hline 2017 & $29,695.0$ & 34.6 & 0.117 & 69.0 & 0.232 & 6.4 & 0.021 \\
\hline 2018 & $31,604.3$ & 90.5 & 0.286 & -4.1 & -0.013 & 16.9 & 0.053 \\
\hline
\end{tabular}

Fuente: Elaboración propia con base en datos de la Secretaría de Economía al mes de mayo (2019a), disponible en: https://www.gob.mx/se/acciones-y-programas/comercio-exterior

do. Además de una competitividad que requiere de ser fortalecida, así como canalizar grandes inversiones en ciencia y tecnología orientadas a la especialización y a su complementariedad en todo tipo de procesos económicos en el contexto de Asia Pacífico. Situación que, más aún, frente a la renegociación del Tratado de Libre Comercio con América del Norte, se enfrenta con fuerzas neoproteccionistas que obligan a mirar hacia sus propios mercados internos, que integrados representan un área de oportunidad altamente factible de ser aprovechada. 
Para concluir, cabe decir en este artículo, se presentó un análisis del panorama reciente de la evolución de la AP en términos de los objetivos de la integración económica que pretende dicha alianza. Particularmente de la relación existente entre competitividad, inversión en ciencia y tecnología de países de la AP, en tanto esquema de integración económica. Los datos descritos y analizados ponen en evidencia que, los países de la AP enfrentan dos grandes retos: el primero de ellos será fomentar el mercado interno, para hacer robusta su relación comercial; el segundo, fortalecer su competitividad, para lo cual tendrán que canalizar más recursos a la ciencia y tecnología para, consolidar a su vez, su mercado.

\section{Referencias}

Appleyard, D. \& Field, A. (2003). Economía Internacional. México: McGraw Hill. Alianza del Pacífico. (2019a). Abecé Alianza del Pacífico. Recuperado de https:// alianzapacifico.net/wp-content/uploads/2015/06/abc_AP.pdf

Alianza del Pacífico. (2019b). Documentos, Protocolo Comercial. Recuperado de https://alianzapacifico.net/documentos/

Arredondo, F., Vázquez, J. C., \& de la Garza, J. (2016). Factores de innovación para la competitividad en la Alianza del Pacífico. Una aproximación desde el Foro Económico Mundial. Estudios Gerenciales, 32(141), 299-308. doi: 10.1016/j.estger.2016.06.003

Balassa, B. (1980). Teoría de la integración económica. México: UTHEA.

Banco Mundial (BM). (2019a). Crecimiento del PIB (\% anual). Recuperado de https://datos.bancomundial.org/indicador/NY.GDP.MKTP.KD.ZG?view=chart Banco Mundial (BM). (2019b). Datos, Ciencia y Tecnología. Recuperado de https://datos.bancomundial.org/indicador

Banco Mundial (BM). (2019c). Datos, Comercio. Recuperado de https://datos. bancomundial.org/indicador

Banco Mundial (BM). (2019d). Datos, Economía y Crecimiento. Recuperado de https://datos.bancomundial.org/indicador

Banco Mundial (BM). (2019e). Exportaciones de bienes y servicios (\% del PIB).

Recuperado de https://datos.bancomundial.org/indicador/NE.EXP.GNFS. ZS?view=chart

Banco Mundial (BM). (2019f). Gasto en investigación y desarrollo (\% del PIB).

Recuperado de https://datos.bancomundial.org/indicador/GB.XPD.RSDV. GD.ZS?view=chart 
Banco Mundial (BM). (2019g). Importaciones de bienes y servicios (\% del PIB). Recuperado de https://datos.bancomundial.org/indicador/NE.IMP.GNFS. ZS?view=chart

Banco Mundial (BM). (2019h). INB per cápita, PPA (a \$ internacionales actuales). Recuperado de https://datos.bancomundial.org/indicador/NY.GNP.PCAP.PP.CD Banco Mundial (BM). (2019i). Investigadores dedicados a investigación y desarrollo (por cada millón de personas). Recuperado de https://datos.bancomundial. org/indicador/SP.POP.SCIE.RD.P6?view=chart

Krugman, P. R., Obstfeld, M., \& Melitz, M. J. (2012). Economía Internacional: teoría y política. Madrid: Pearson Educación.

North, D. (1993). Instituciones, cambio institucional y desempeño económico. México D.F.: FCE.

Organización Mundial del Comercio (OMC). (2019). Los 128 países que han firmado el Acuerdo General antes de finalizar 1994. Recuperado de https:// www.wto.org/spanish/thewto_s/gattmem_s.htm

Porter, M. (1999). La Ventaja Competitiva de las Naciones. Argentina: Vergara. Schettino, M. (1995). Economía Internacional. México: Grupo Editorial Iberoamérica.

Secretaría de Economía (SE). (2019a). Comercio Exterior. Recuperado de http:// www.economia-snci.gob.mx/sic_php/pages/estadisticas/

Secretaría de Economía (SE). (2019b). Competitividad y Normatividad. Recuperado de https://www.gob.mx/se/acciones-y-programas/comercio-exterior

Shahid, Y. \& Stiglitz, J. (2002). Aspectos del desarrollo: Resueltos y pendientes. En G. M. Meier \& J. E. Stiglitz (Coords.), Fronteras de la economía del desarrollo. El futuro en perspectiva (pp. 219-262). México D.F.: Banco Mundial y Alfaomega.

The World Economic Forum (WEF). (2019). Reports 2009-2018. Recuperado de https://www.weforum.org/reports 